\title{
Mercado de carne de frango brasileiro no contexto dos novos acordos regionais de comércio: Transpacífico e Transatlântico
}

\author{
The Brazilian chicken meat market in the context of \\ the new regional trade agreements: Trans-pacific and \\ Transatlantic
}

\author{
Angélica Pott de Medeiros ${ }^{1}$ (D) e Reisoli Bender Filho ${ }^{1}$
}

\begin{abstract}
Resumo: O estudo tem por objetivo examinar os possíveis impactos da implementação dos acordos Transpacífico e Transatlântico sobre o mercado de carne de frango brasileiro. A metodologia aplicada deriva de um Modelo de Equilíbrio Espacial na forma de um Problema de Complementaridade Mista (PCM), baseando na simulação de cinco cenários alternativos, cujo objetivo foi evidenciar possíveis mudanças no mercado da carne de frango decorrentes da implementação de novos acordos comerciais. Os resultados indicam que, de maneira geral, com a efetivação de ambos os acordos, o setor de carne de frango brasileiro pode invariavelmente ter prejuízos, principalmente no que se refere à produção e, em consequência, afetar os preços e os excedentes dos produtores. Os cenários mais prejudiciais ao Brasil consistem na formação do TPP em sua forma mais ampla, baseando-se na eliminação das barreiras tarifárias e não tarifárias, como também na formação simultânea dos acordos, nos quais o País apresenta perda líquida de bem-estar. A partir disso, ressalta-se a importância da negociação de acordos comerciais para garantir ao setor condições de expansão e acesso a novos mercados.
\end{abstract}

Palavras-chaves: mercado internacional de carne de frango, acordos comerciais e integração regional, TPP, TTIP, equilíbrio espacial.

Abstract: The study aims to examine the possible impacts of the Transpacific and Transatlantic agreements on the Brazilian chicken meat market. The methodology derives from a Spatial Equilibrium Model as a Mixed Complementarity Problem (MCP), based on five alternative scenarios, which aimed to highlight possible changes in the market of chicken meat from the implementation of new

Data de submissão: 10 de abril de 2017. Data de aceite: 7 de dezembro de 2018.

1. Universidade Federal de Santa Maria (UFSM), Santa Maria (RS), Brasil. E-mails: apm_angelica@ yahoo.com.br; reisolibender@yahoo.com.br 
trade agreements. The results indicate that, in general, with the implementation of both agreements the Brazilian chicken meat market may invariably cause losses, particularly in relation to production, consequently, affect producers' prices and surpluses. The most damaging scenarios for Brazil are the formation of the TPP in its broadest form, based on the elimination of tariff and non-tariff barriers, as well as the simultaneous formation of the agreements, in which the country shows a net loss in welfare. From this, we emphasize the importance of negotiating trade agreements to ensure the industry conditions of expansion and access to new markets.

Keywords: international chicken meat market, trade agreements and regional integration, TPP, TTIP, spatial equilibrium.

Classificação JEL: C61, F13, F15.

\section{Introdução}

A recente crise econômico-financeira lançou sobre a economia global uma severa recessão, que também fragmentou o Sistema Multilateral de Comércio (SMC), o qual é centrado na Organização Mundial do Comércio (OMC) e integrado por inúmeros acordos preferenciais. Com isso, as negociações da Rodada Doha ${ }^{1}$ foram bloqueadas em 2008 por falta de interesse político de seus membros em concluir as próximas etapas da liberalização e a definição das novas regras de comércio internacional (Thorstensen, 2012).

Assim, na contramão das negociações de âmbito multilateral, nos anos recentes, junto à recuperação econômica, os países desenvolvidos que foram fortemente impactados sinalizaram a recuperação, liderando as negociações de dois grandes acordos no comércio internacional, a Parceria Transpacífico ${ }^{2}$ e a Parceria Transatlântica ${ }^{3}$ de comércio e investimento (TPP e TTIP, respectivamente). O primeiro, de maior abrangência, envolve 12 países, que, conjuntamente, representam cerca de $40 \%$ da economia mundial, e o segundo está estabelecido entre os Estados Unidos e a União Europeia (Thorstensen, 2012; Monteiro, 2014).

\footnotetext{
1 A Rodada Doha foi a última rodada de negociações multilaterais sob o sistema GATT-OMC (Brasil, 2016).

2 O Acordo Transpacífico é composto pelos seguintes países: Nova Zelândia, Chile, Brunei, Cingapura, Austrália, Canadá, Japão, Malásia, México, Peru, Estados Unidos e Vietnã.

3 O Acordo Transatlântico é formado pela União Europeia e pelos Estados Unidos.
}

Único país integrante de ambos os acordos, os Estados Unidos, frente ao crescimento da China no comércio mundial, têm buscado acordos de livre comércio que excluem a economia asiática para reforçar a sua posição competitiva no comércio internacional (Aslan et al., 2015). Nestas condições, dada a relevante participação dos países-membros no comércio mundial, o TPP e o TTIP poderão afetar a economia tanto dos seus próprios membros quanto dos não membros, alterando as relações e o direcionamento dos fluxos comerciais.

Estes acordos criarão quotas e ampliarão o acesso preferencial a serviços, combinado com uma densa regularização de instrumentos para o comércio bilateral e regional, causando impactos potenciais também em países que não participam de forma intensiva de tais acordos, caso do Brasil, que, embora competitivo na produção agrícola e em commodities, em muitas situações, tem acesso limitado a diversos mercados. Conforme discutem Thorstensen \& Ferraz (2014a), o TTIP e o TPP implicarão a redução dos fluxos de importação e de exportação, colaborando, com isso, para o distanciamento do Brasil dos mercados externos.

A partir desta nova configuração, a concorrência entre os Estados Unidos e o Brasil tenderá a aumentar, em muitos produtos, caso da carne de frango, em cuja produção mundial o país norte-americano ocupa a primeira posição, enquanto que o Brasil é o maior exportador do produto (United States Department of Agriculture Foreign Agricultural Service, 2016a). Sendo assim, para o Brasil, tornar-se-á um desafio manter a posição alcançada e ainda conquistar novos 
mercados, tendo em vista que os EUA irão continuar disputando a colocação de maior exportador de carne de frango, buscando melhorar sua produção e expandir seu mercado consumidor (Sousa \& Osaki, 2005). Considerando a efetivação destes novos arranjos de comércio, o presente estudo tem como objetivo examinar os possíveis impactos da implementação dos acordos Transpacífico (TTP) e Transatlântico (TTIP) sobre o mercado de carne de frango brasileiro. Neste sentido, análises de mudanças na estrutura comercial dos países já foram desenvolvidas, contudo, tais estudos se concentraram em verificar o impacto em diversos setores dos países-membros e não membros, a partir das propostas de eliminação das barreiras tarifárias e não tarifárias (François et al., 2013; Berden et al., 2009; Centre for Economic Policy Research, 2013; Lima et al., 2014; Aslan et al., 2015; Burfisher et al., 2014; Petri \& Plummer, 2016; Thorstensen \& Ferraz, 2014b; Silva et al., 2015; Silva, 2016). Todavia, observa-se que a temática proposta não possui discussão mais detalhada na literatura, dado que, no debate acerca dos possíveis impactos gerados pelos acordos Transatlântico e Transpacífico, não foram encontrados estudos que enfatizassem setores específicos, caso do setor de carne de frango brasileiro.

Assim sendo, a referida proposta encontra espaço ao mesmo tempo em que se sustenta devido à importante participação do segmento de carnes na economia brasileira, sobremaneira na pauta exportadora, pois a carne de frango está entre os principais produtos, sendo que, em 2015, figurou como o quarto produto mais exportado pelo Brasil, enquanto em 2016 o produto passou a ocupar a quinta posição, com participação de aproximadamente $3 \%$ do total exportado, atrás apenas da soja em grão, do minério de ferro, petróleo e do açúcar (Avisite, 2015).

Para atender ao desenvolvimento do problema proposto, o trabalho está constituído em mais quatro seções, além da introdução. Na seção dois, discorre-se sobre evidências empíricas acerca dos impactos dos acordos em questão. Na seção três, é detalhada a abordagem metodológica, a qual está baseada no Modelo de Equilíbrio Espacial estruturado em um Problema de Complementaridade Mista. Em seguida, na seção quatro, apresentam-se os resultados do estudo e, por fim, na quinta seção, delineiam-se as principais conclusões do estudo.

\section{Impactos dos acordos Transpacífico e Transatlântico no comércio: evidências empíricas}

Dada a importância dos acordos e os seus impactos que extrapolam seus países-membros, diversos estudos buscaram quantificar os efeitos dos acordos comerciais nas economias, tanto dos membros quando dos não membros. Enfatizando o TTIP, Berden et al. (2009) buscaram verificar os impactos das reduções tarifárias e não tarifárias sobre as economias da União Europeia e dos Estados Unidos, assim como François et al. (2013), Centre for Economic Policy Research (2013) e Lima et al. (2014). Já Aslan et al. (2015) levaram em consideração os impactos do TTIP na economia Chinesa e, de forma mais específica, Silva et al. (2015) analisaram os possíveis impactos do TTIP no Mercosul. E Silva (2016) enfatizou a economia brasileira e suas regiões.

Já em relação aos impactos do TPP, Burfisher et al. (2014) desenvolveu sua análise com ênfase nos impactos sobre os países-membros do acordo, enquanto que, de forma mais abrangente, Thorstensen \& Ferraz (2014b) verificaram os possíveis efeitos do TPP e do TTIP na economia brasileira, além de estimar os efeitos caso o Brasil pertencesse ao TTIP.

Em suma, tais estudos apontam impactos significativos do TTIP tanto para a economia dos Estados Unidos quanto para a União Europeia, estimando-se aumento no PIB, nas exportações líquidas e no bem-estar (François et al., 2013; Berden et al., 2009; Lima et al., 2014). Levando-se em consideração o mesmo acordo, porém em análise para outras economias, o estudo de Aslan et al. (2015) aponta que o TTIP afetaria negativamente a China, sendo que tal impacto se agravaria caso o TPP também fosse realizado, porém, caso a China participasse do TPP, suas variáveis econômicas seriam impactadas positivamente.

Já para o Brasil, o TTIP reduziria em $0,25 \%$ as exportações do agronegócio e aumentaria em $0,01 \%$ as importações (Lima et al., 2014). Ainda, foram verificadas perdas na balança comercial, no PIB e no comércio. E, se o Brasil viesse a participar do acordo, apresentaria aumento em suas exportações (Thorstensen \& Ferraz, 2014b). Ademais, Silva et al. (2015) verificaram que o TTIP afetaria de forma positiva a China e o Mercosul, destacando-se os setores de soja e madeira.

Em relação ao TPP, Burfisher et al. (2014) constatou que aumentaria o comércio agrícola para o Japão, e que 
os Estados Unidos captariam um terço das exportações agrícolas do TPP, corroborando com Petri \& Plummer (2016), os quais verificaram que o TPP beneficiaria os países membros, sobremaneira os Estados Unidos. Para o Brasil, Thorstensen \& Ferraz (2014b) verificaram que tal acordo causaria impactos negativos para a economia, com o País perdendo espaço no mercado internacional.

A partir de tais evidências, constata-se que os resultados, tanto para os países-membros como para os não membros, ainda não são plenamente previstos, sendo que dependerão sobremaneira de quais questões serão efetivamente negociadas, como também da formatação dos acordos. Ademais, destaca-se que os estudos utilizaram do Modelo de Equilíbrio Geral Computável, e o método utilizado nesse estudo consiste em um Modelo de Equilíbrio Espacial, possibilitando uma análise mais detalhada dos efeitos das mudanças no cenário comercial sob um setor específico, caso da carne de frango.

\section{Metodologia}

\subsection{O Modelo de Equilíbrio Espacial e o Problema de Complementaridade Mista}

A metodologia aplicada deriva de um modelo de otimização na forma de um Problema de Complementaridade Mista (PCM), oriundo do Modelo de Equilíbrio Espacial idealizado por Samuelson (1952), que formaliza o conceito de maximização, no qual se somam os excedentes do produtor e do consumidor para chegar a um ponto ótimo global, intitulado como função de ganho social líquido (Net Social Payoff-NSP).

Fundamentado no problema de otimização (NSP), Alvim \& Waquil (2007) apresentam o Problema de Complementaridade Mista (PCM), tendo como vantagem a facilidade de inserir tarifas no modelo. Desta forma, o PCM propicia a simulação de mudanças de ordem política, as quais operam sobre os preços de mercado, caso das barreiras tarifárias. Neste caso, as equações podem ter igualdade e desigualdades, sendo que o objetivo da centralização desse problema parte das funções de demanda e oferta e das condições de Kuhn-Tucker (Gründling \& Waquil, 2015). As condições do PCM, incluindo os instrumentos de política comercial, são apresentadas nas seguintes equações: $\varphi_{i} \geq 0, \quad\left(\sum_{j}^{J} X_{i, j}-q_{i}^{s}\right) \cdot \varphi_{i}=0, \forall_{i, j}$

$\lambda_{j} \geq 0, \quad\left(q_{j}^{d}-\sum_{i}^{I} X_{i, j}\right) \cdot \lambda_{j}=0, \forall_{i, j}$

$X_{i, j} \geq 0, \quad\left(\lambda_{j}-\left(\varphi_{i}+t_{i, j}\right) \cdot\left(1+\operatorname{tar}_{i, j}+q r_{i, j}\right)\right) \cdot X_{i, j}=0, \forall_{i, j}$

$q r_{i, j} \geq 0, \quad\left(Q_{i, j}-X_{i, j}\right) \cdot q r_{i, j}=0, \forall_{i, j}$

em que $i, j$ são as regiões; $q_{j}^{d}$ é a quantidade consumida na região $j ; q_{i}^{s}$ é a quantidade produzida na região $i$; $X_{i, j}$ é a quantidade de produto comercializada entre as regiões $i$ e $j ; t_{i, j}$ é o custo de transporte entre as regiões $i$ e $j ;$ tar $_{i, j}$ é a tarifa imposta sobre o produto da região $i$ na região $j ; q r_{i, j}$ é a tarifa aplicada quando o fluxo exceder a quota tarifária $\left(Q_{i, j}\right) ; \lambda_{j}$ multiplicador de Lagrange: preço-sombra na região produtora $j ; \varphi_{i}$ multiplicador de Lagrange: preço-sombra na região consumidora $i$.

As Equações 1 e 2 permitem obter os preços-sombra, os quais definem o preço máximo que o consumidor está disposto a pagar pela unidade adicional do produto e o preço mínimo que o produtor está disposto a receber para produzir uma unidade adicional do produto, além de obter as quantidades consumidas e produzidas e os fluxos comerciais.

Por sua vez, as Equações 3 e 4 estabelecem os fluxos comerciais entre as regiões, incorporando ao Modelo de Equilíbrio Espacial instrumentos de política comercial, tais com as tarifas (ad valorem ou específicas), os subsídios, as quotas tarifárias e as barreiras não tarifárias (normas técnicas, sanitárias e fitossanitárias), e ainda considera o custo de transporte entre as regiões (Bender Filho \& Alvim, 2007).

Baseando-se nesta metodologia, pretende-se quantificar os ganhos ou perdas para o mercado brasileiro de carne de frango resultantes da implementação de novos acordos comerciais: Acordo de Parceria Transatlântica de Comércio e Investimento (TTIP) e a Parceria Transpacífico (TPP), a partir da aplicação das medidas discutidas em tais acordos, as quais se baseiam na eliminação das barreiras comerciais de forma parcial e/ ou total.

Para resolver este problema, foram propostos cinco cenários, conforme descrito no Quadro 1, nos quais são removidas as barreiras de comércio, de acordo com a discussão dos acordos TTIP e TTP, buscando verificar os impactos na produção e nos fluxos comerciais internacionais brasileiros de carne de frango. 
Quadro 1. Cenários propostos

\begin{tabular}{|c|c|c|c|}
\hline Acordos & Cenários & Tarifas & BNT** \\
\hline \multirow{2}{*}{ Acordo Transpacífico } & 1 & Redução de 40\% & Manutenção \\
\cline { 2 - 4 } & 2 & Eliminação & Manutenção \\
\hline \multirow{2}{*}{ Acordo Transatlântico } & 3 & Redução de 40\% & Eliminação \\
\cline { 2 - 4 } & 4 & Eliminação & Eliminação \\
\hline Acordos Simultâneos* & 5 & Eliminação & \\
\hline
\end{tabular}

Fonte: elaborado pelos autores.

* Pressupõe a ocorrência simultânea do Acordo Transpacífico e do Acordo Transatlântico. ** Barreiras não tarifárias (BNT).

Estes cenários foram formulados com base nas condições que constam nas negociações dos Acordos TPP e TTIP. Inicialmente, o cenário 1 simula uma eliminação parcial de $40 \%$ das barreiras tarifárias e a manutenção das barreiras não tarifárias para o TPP, conforme estabelecido em United States Trade Representative (2014), que estipula uma redução de $40 \%$ nos impostos de exportação à carne de frango dos Estados Unidos, decorrentes da efetivação do Acordo do Transpacífico; já o cenário 2 amplia as condições comerciais entre os membros do TPP ao pressupor a eliminação total das barreiras tarifárias e não tarifárias, permitindo o livre comércio de produtos, conforme consta no calendário de eliminação tarifária da Parceria Transpacífico (United States Trade Representative, 2015).

Os cenários 3 e 4 consideram a implementação do acordo TTIP. Especificamente, o cenário 3 simula a eliminação parcial de $40 \%$ das barreiras tarifárias, seguindo a proposta da United States Trade Representative (2014), enquanto que o cenário 4 pressupõe a eliminação total das barreiras tarifárias e não tarifárias, tendo em vista que o acordo TTIP, além das tarifas, tem discutido a padronização das questões não tarifárias, tais como normas técnicas, questões sanitárias e fitossanitárias e de bem-estar animal. Em isso ocorrendo, o cenário que será simulado sugere a eliminação total de tais barreiras, pela suposição de livre comercialização de produtos entre os membros do acordo.

Complementando, o cenário 5 pressupõe a ocorrência simultânea de tais acordos, eliminando-se as barreiras tarifárias e não tarifárias aos seus países membros, tendo em vista que o TPP está sendo implementado e, para o TTIP, espera-se a conclusão ainda em 2016 (European Comission, 2016).

Os dados necessários à implementação do Modelo de Equilíbrio Espacial como um Problema de
Complementaridade Mista foram colhidos no banco de dados da Food and Agriculture Organization (Food and Agricultural Organization of the United Nations, 2016), utilizando o período entre 2011 e 2013, últimos anos disponíveis para o mercado de carne de frango. Operacionalmente, foi utilizado o solver MILES, pertencente ao Gams (General Algebraic Modelling System), criado em 1994.

Também são necessárias as elasticidades-preço de demanda e de oferta, variáveis que são utilizadas para definir as funções de oferta e demanda que geram as Equações (1) e (2) ${ }^{4}$. Ambas as variáveis foram coletadas na base de dados da United States Department of Agriculture. Foreign Agricultural Service (2016b), referente às carnes em geral. Fez-se necessário usar tais dados em função da inexistência das elasticidades específicas à carne de frango para todas as regiões estudadas. No caso das regiões que englobam vários países, utilizaram-se as elasticidades do país mais significativo na produção e no consumo do produto.

Ainda, fizeram-se necessários os dados das barreiras tarifárias, barreiras não tarifárias, subsídios e custos de transporte. As barreiras tarifárias (ad valorem) bem como as barreiras não tarifárias (sanitárias, fitossanitárias e técnicas) foram obtidas a partir do banco de dados da Organização Mundial do Comércio (2016). No caso de regiões, foram estimadas as tarifas médias, considerando-se as tarifas dos países-membros das regiões estabelecidas. Já no caso das barreiras não tarifárias, consideraram-se os países e / ou regiões que as aplicam, sendo consideradas barreiras técnicas e/ ou medidas sanitárias e fitossanitárias. Em relação aos subsídios à produção, foram considerados os repasses médios aos produtores de frangos, entre 2002

4 A estrutura completa de equações que fundamenta o Problema de Complementaridade Mista pode ser encontrada em Alvim (2010). 
e 2004, últimos anos disponíveis, conforme a Organization for Economic Co-operation and Development (2005).

Ademais, foram necessários os custos totais de transporte da carne de frango entre as regiões/países estudados, os quais foram calculados baseando-se nos custos portuários de acordo com o Porto do Rio Grande (2016) e o simulador de preço de exportação do Brasil (2016), obtendo-se, a partir disso, o custo em US\$ da tonelada por milha marítima, para posterior cálculo do custo, o qual levou em consideração as distâncias das regiões / países conforme informações do Banco Mundial.

O trabalho abrange o mercado global de carne de frango, incluindo todos os países consumidores, produtores, exportadores e importadores. Para facilitar a modelagem e a análise dos cenários alternativos, alguns países foram agrupados em regiões. Para tanto, inicialmente, buscou-se manter os países membros do TPP e do TTIP desagregados, assim como os países que possuem relações comerciais com o Brasil, possibilitando a identificação das alterações nos fluxos comerciais específicos de cada país. Detalhadamente, o modelo foi delimitado em 20 regiões, conforme Quadro 2.

Em destaque, as regiões que constituíram o TPP nas simulações foram Peru, Estados Unidos, restante do Nafta, Austrália, Malásia, Japão e demais do TPP, este último agrupa o Chile, Nova Zelândia, Brunei, Cingapura e Vietnã, países que possuem menor participação de marcado em relação ao produto analisado. Quanto ao TTIP, as regiões determinadas são os Estados Unidos e a União Europeia. Ressalta-se que as simulações dos cenários levaram em consideração a participação dos Estados Unidos nos referidos acordos comerciais, porém, em 23 de janeiro de 2017, o recém-empossado presidente dos Estados Unidos, Donald Trump assinou o decreto que retirou o país do acordo com os países do Pacífico.

\section{Resultados e discussão dos cenários propostos}

\subsection{Cenário-base e calibragem do modelo}

A validação das simulações corresponde à comparação do cenário-base (valores estimados) com os valores observados (reais), relação que permite verificar a robustez do modelo. Porém, Thompson (1981, apud Waquil, 1995) salienta algumas razões pelas quais o Modelo de Equilíbrio Espacial pode não retratar todo o comércio observado, principalmente pelos produtos não serem perfeitamente homogêneos e pela imposição de padrões e restrições sanitárias diferentes entre as regiões, o que ocasiona pequenas diferenças entre os fluxos de comércio observados e os estimados, mas sem invalidar os resultados.

Em geral, observou-se que, entre os valores estimados e observados, houve diferença máxima de $8 \%$, indicando que o cenário-base pode ser validado, pois os resultados estimados são condizentes com os valores observados, aqueles encontrados nas relações comerciais reais. Ademais, verificou-se que, no cenário-base, o modelo

Quadro 2. Distribuição das regiões na construção dos cenários alternativos

\begin{tabular}{|c|c|l|c|c|l|}
\hline & Abreviação & \multicolumn{1}{|c|}{ Países/Regiões } & Abreviação & \multicolumn{1}{|c|}{ Países/Regiões } \\
\hline 1 & bra & Brasil & 11 & afr & África \\
\hline 2 & arg & Argentina & 12 & ome & Demais do Oriente Médio \\
\hline 3 & mcs & $\begin{array}{l}\text { Restante do Mercosul (Paraguai, Uruguai } \\
\text { e Venezuela) }\end{array}$ & 13 & sau & Arábia Saudita \\
\hline 4 & per & Peru & 14 & jpn & Japão \\
\hline 5 & das & Demais da América do Sul & 15 & asi & Demais da Ásia \\
\hline 6 & usa & Estados Unidos & 16 & chn & China \\
\hline 7 & naf & Restante do Nafta (Canadá e México) & 17 & rus & Rússia \\
\hline 8 & aus & Austrália & 18 & ue28 & União Europeia (28) \\
\hline 9 & mas & Malásia & 19 & tpp & $\begin{array}{l}\text { Demais membros do TPP (Chile, Nova } \\
\text { Zelândia, Brunei, Cingapura e Vietnã). }\end{array}$ \\
\hline 10 & ase & Demais do Asean & 20 & rm & Resto do Mundo \\
\hline
\end{tabular}

Fonte: Elaborado pelos autores. 
foi coerente em relação aos fluxos comerciais da carne de frango, pois expôs relações comerciais condizentes com os fluxos reais. De acordo com o cenário-base, os principais produtores da commodity são os Estados Unidos, a China, o Brasil e a União Europeia. Também retratou os maiores consumidores, caso dos Estados Unidos, da China, da União Europeia, do Brasil e dos países do Oriente Médio.

Em relação aos fluxos de comércio, considerando os principais exportadores, verifica-se que os Estados Unidos concentram suas exportações para os países do Nafta, África e alguns países da Ásia, enquanto que o Brasil exporta para os países do Oriente Médio, com destaque à Arábia Saudita, além do Japão e de alguns países dos demais membros do TPP.

Tendo em vista tais evidências, considera-se que o modelo-base atendeu às condições de validação, pois os resultados simulados reproduziram consistentemente o cenário real. A partir disso, são analisados os resultados obtidos por meio da simulação dos cenários alternativos em relação à variação da produção, consumo, preços e excedentes do produtor e do consumidor e fluxos comerciais.

4.2. Análise dos impactos da implementação dos cenários alternativos - Acordos TPP e TTIP - sobre mercado mundial e brasileiro de carne de frango

\subsubsection{Análise das variações dos níveis de produção}

A análise se restringe às informações referentes à produção em valores relativos ao cenário-base, conforme Tabela 1. Inicialmente, levando em consideração o cenário 1, o qual pressupõe a redução de $40 \%$ das barreiras tarifárias e a manutenção das barreiras não tarifárias para o acordo TPP, observa-se, de maneira geral, perdas marginais em termos de produção para os países do Mercosul, de cerca de $0,1 \%$. Porém, tal redução representa cerca de 9.600 toneladas. O mesmo ocorre com os países do Oriente Médio e da Arábia Saudita, cuja redução é de cerca de 3.700 toneladas, assim como para os demais membros

Tabela 1. Variações da produção nos cenários alternativos em relação ao cenário-base (\%)

\begin{tabular}{|c|c|c|c|c|c|}
\hline Região & Cenário 1 & Cenário 2 & Cenário 3 & Cenário 4 & Cenário 5 \\
\hline bra & $-0,1$ & $-7,3$ & 0,0 & $-2,7$ & $-6,0$ \\
\hline $\arg$ & $-0,1$ & $-6,4$ & 0,0 & $-2,2$ & $-4,9$ \\
\hline mcs & $-0,1$ & $-8,9$ & 0,0 & $-3,0$ & $-6,9$ \\
\hline per & 0,0 & 15,8 & 0,0 & 3,3 & 19,9 \\
\hline das & 0,0 & 0,2 & 0,0 & 0,0 & 1,2 \\
\hline usa & 0,0 & 2,6 & 0,0 & 2,3 & 3,2 \\
\hline naf & 0,0 & 11,1 & 0,0 & 9,9 & 13,8 \\
\hline aus & 0,4 & $-2,3$ & 0,0 & $-0,1$ & $-1,5$ \\
\hline mas & 0,0 & $-12,8$ & 0,0 & 0,0 & $-10,4$ \\
\hline ase & 0,2 & $-5,3$ & 0,0 & $-0,3$ & $-3,5$ \\
\hline afr & 0,0 & 18,5 & 0,0 & 16,6 & 20,4 \\
\hline ome & $-0,1$ & $-5,2$ & 0,0 & $-1,9$ & $-4,3$ \\
\hline sau & $-0,1$ & $-5,3$ & 0,0 & $-8,1$ & $-4,7$ \\
\hline jpn & 0,0 & $-7,5$ & 0,0 & $-1,0$ & $-6,7$ \\
\hline asi & 0,0 & 14,8 & 0,0 & 13,2 & 15,7 \\
\hline chn & 0,0 & 0,0 & 0,0 & 0,0 & 0,0 \\
\hline rus & 0,0 & 0,0 & 0,0 & 0,0 & 0,0 \\
\hline ue28 & 0,0 & 0,0 & 0,0 & $-7,6$ & $-5,7$ \\
\hline tpp & $-0,1$ & $-7,3$ & 0,0 & $-1,9$ & $-5,0$ \\
\hline $\mathbf{r m}$ & 0,0 & $-0,5$ & 0,0 & 0,0 & 0,0 \\
\hline
\end{tabular}

Fonte: Resultados da pesquisa. 
do TPP, os quais têm seus quantitativos reduzidos em aproximadamente 732 toneladas.

Em contrapartida, a Austrália e os demais países do Asean apresentam crescimento em seus níveis, ainda que de pequena magnitude, de $0,4 \%$ e $0,2 \%$, respectivamente, resultado que representa um aumento de aproximadamente 3.700 e 8.000 toneladas. Tal comportamento se deve à redução de barreiras tarifárias entre os membros do acordo, influenciando nas condições produtivas da Austrália e acarretando a redução da produção do Brasil e dos demais países do Mercosul.

Supõe-se que esse direcionamento aos países intrabloco estimulará o incremento da produção da Austrália. Ademais, de acordo com os fluxos comerciais, os demais países do Asean anteriormente importavam o produto da Austrália, porém, a região apresenta barreiras tarifárias elevadas, sendo que, com a simulação do primeiro cenário, a Austrália passará a exportar esse quantitativo ao Japão, caracterizando um desvio de comércio, forçando os demais países do Asean a produzirem ou importarem para suprir sua demanda interna. Além disso, a Austrália acaba substituindo uma fatia do mercado japonês que era atendida pelo produto brasileiro devido à facilitação de comércio vigorado.

Nas demais regióes não foram verificadas mudanças expressivas, principalmente pelo fato de as regiões pertencentes ao TPP já possuírem tarifas baixas (em sua maioria menores que 10\%), mesmo porque o cenário simulou apenas a redução tarifária.

No cenário 2, as barreiras tarifárias dos membros do TPP foram integralmente eliminadas, assim como as barreiras não tarifárias, influenciando de forma mais expressiva as regiões observadas, em destaque novamente o Brasil, o qual apresenta uma redução de 7,3\%, perfazendo uma diminuição de mais de 800.000 toneladas. Para os demais países que compõem o Mercosul, no modelo representado pela Argentina e restante do Mercosul (arg e mcs), tal redução atinge 6,4\% e 8,9\%, respectivamente; em termos de volume, representa uma redução na produção de cerca de 126.000 toneladas. Nesta situação, o Mercosul como um todo deduz de sua produção aproximadamente 1 milhão de toneladas.

Tal redução também é observada nos demais países do Asean, demais países do Oriente Médio, Arábia Saudita e no resto do mundo, com baixas de 5,3\%, 5,2\%, 5,3\% e $0,5 \%$, respectivamente. Conjuntamente, perfazem redução de cerca de 700.000 toneladas produzidas. Observa-se também queda na produção de países como Austrália, Malásia, Japão e demais países do TPP, os quais são membros do acordo. Quantitativamente, corresponde a reduções de $2,3 \%, 12,8 \%, 7,5 \%$ e de $7,3 \%$, subtraindo de seus quantitativos cerca de 400.000 toneladas.

No entanto, regiões como os demais países da América do Sul, da África e da Ásia expandiram seus volumes de produção em $0,2 \%, 18,5 \%$ e 14,8\%, respectivamente. Igual cenário foi verificado no Peru (19\%), nos Estados Unidos (3\%) e nos demais países do Nafta (11\%), resultados que quantitativamente representam acréscimo de 1 milhão de toneladas produzidas. Ressalta-se que esses países são pertencentes ao Acordo Transpacífico.

A partir destas evidências, observa-se a centralização da produção nos países do Nafta, os quais, em grande medida, compensaram a redução da produção dos países do Mercosul, assim como dos países-membros do TPP que tiveram sua produção reduzida. Em relação à redução do quantitativo dos demais países do TPP, dentre eles o Chile, a Nova Zelândia, o Brunei, a Cingapura e o Vietnã, sugestiona-se que esse fato se deve ao desvio de comércio à outra região, sendo que os países que possuírem maiores produtividades, melhores condições de produção e preços mais baixos, caso do Peru, dos Estados Unidos e dos demais países do Nafta, serão beneficiados com o acordo.

Em se tratando da simulação do cenário 3, que supõe a eliminação parcial de barreiras tarifárias e a manutenção das barreiras não tarifárias do TTIP, de maneira geral não se verificaram alterações significativas à produção de carne de frango nas regiões analisadas. Tal resultado se deve ao fato de que apenas a União Europeia e os Estados Unidos são membros do acordo e, principalmente, pelo fato de que a redução se fez apenas nas barreiras tarifárias, as quais, entre ambos os países, já é reduzida, o que ratifica a forte influência das barreiras não tarifárias nas relações de comerciais. Por outro lado, Silva (2016) estimou, a partir da redução tarifária no TTIP, perdas nos níveis de produção, exportação e importação no setor de carnes e animais vivos, comportamento que também se aplica aos demais produtos do agronegócio brasileiro. Diante do mesmo cenário, Silva et al. (2015) analisaram os impactos para a China e para o Mercosul, principais parceiros comerciais do Brasil e, especificamente no setor de carnes e animais vivos, constatou-se a redução da produção do Mercosul, acompanhada de aumento das exportações e redução das importações. 
Diferentemente, no cenário 4, onde se simulou a eliminação das barreiras tarifárias e não tarifárias no TTIP, verifica-se ampla abrangência de mudanças comerciais e resultados expressivos nas regiões estudadas. Para o Brasil, assim como nos demais cenários, a produção é reduzida em aproximadamente $3 \%$, equivalente a 300.000 toneladas. Quanto ao restante do Mercosul, a redução representa cerca de 40.000 toneladas. A diminuição, ainda que em menor magnitude, também afeta países como a Austrália $(0,1 \%)$, demais países do Asean $(0,3 \%)$, demais países do Oriente Médio (2\%), Arábia Saudita (8\%), Japão (1\%), União Europeia (8\%) e os outros países do TPP $(2 \%)$. Esses resultados vão de encontro com os achados de Silva et al. (2015) e Silva (2016), os quais verificaram aumentos em termos de produção do setor de carnes e animais vivos do Brasil e do Mercosul, decorrente da liberalização comercial, bem como um aumento nas exportações dessas regiões.

Estas alterações são motivadas, sobremaneira, pelo efeito do TTIP sobre o Brasil, pois o País acaba perdendo a demanda de um parceiro comercial importante, a Arábia Saudita, que passa a importar carne de frango do bloco europeu. Em compensação, o preço do produto brasileiro reduz, acarretando o aumento da demanda dos países do Oriente Médio, Japão, e demais países do TPP; entretanto, tal expansão não é suficiente para cobrir integralmente as perdas com a Arábia Saudita.

Espacialmente, nos demais países do TPP, essa ampliação das importações provenientes do Brasil ocasiona a redução do mercado consumidor à Argentina e aos demais países do Mercosul devido à competitividade dos preços. Além disso, o Japão, demais países do TPP, demais países do Asean, Oriente Médio, Arábia Saudita e União Europeia reduzem seus quantitativos de produção em decorrência da expansão de suas importações.

Em contrapartida, observam-se acréscimos na produção do Peru (3\%), dos Estados Unidos (2\%), dos países do Nafta (10\%), da África $(17 \%)$ e os da Ásia (13\%). Tais acréscimos se devem, principalmente, ao aquecimento do comércio entre os Estados Unidos e a União Europeia, tendo em vista que o bloco europeu passa a produzir menos carne de frango, passando a importar dos Estados Unidos, o qual apresenta preços mais competitivos. Ainda, verifica-se que a União Europeia absorve o mercado saudita, antes suprido pelo Brasil, decorrente de condições de preço e o custo de transporte favoráveis.
Com o acréscimo nas relações comerciais entre os Estados Unidos e a União Europeia, o país norte-americano acaba reduzindo o quantitativo de suas exportações aos seus principais parceiros comerciais, caso do Nafta, demais países da África e da Ásia, que passam a direcionar suas produções ao mercado doméstico. Essas condições geram alterações nos fluxos comerciais dos demais países da Ásia, os quais passam a importar parte de sua demanda do Peru, em grande medida, pelo preço competitivo.

Por fim, o último cenário pressupôs a ocorrência simultânea dos dois acordos, TPP e TTIP, sendo simulada a eliminação total das barreiras tarifárias e não tarifárias aos membros de ambos os acordos. Estas condições, para o Brasil, acarretariam em redução de $6 \%$ em sua produção, correspondente a uma queda de cerca de 700.000 toneladas; o mesmo ocorreria com o Mercosul, que produziria 800.000 toneladas a menos. Outros países como a Austrália (2\%), a Malásia (10\%), demais países do Asean (4\%), demais países do Oriente Médio (4\%), Arábia Saudita (5\%), Japão (7\%), União Europeia (6\%), e demais países do TPP (5\%) também seriam afetados negativamente.

Com a ocorrência simultânea dos dois referidos acordos, o Brasil amplia seu montante exportado ao Oriente Médio, contudo reduz as relações comerciais com a Arábia Saudita, o Japão e os demais países do TPP, esses dois últimos, membros do TPP. Em compensação, passa a exportar ao Peru, à Austrália e aos demais países da África. Esse resultado muito se deve ao fato de os Estados Unidos não conseguirem atender a todos esses mercados, mesmo com o Peru e a Austrália integrando TPP.

Assim como o Brasil, a Argentina e o restante do Mercosul perdem o mercado dos demais países do TPP, passando a atender à Austrália, que tem reduzido sua produção em decorrência dos preços competitivos praticados no Mercosul. Esses acarretam aumento das exportações australianas de carne de frango aos demais países do Asean, ao mesmo tempo em que reduzem a produção da região. Em suma, a Austrália passa a reexportar carne de frango, a qual é importada dos países do Mercosul e negociada com países do Asean.

Por outro lado, a expansão na produção se concentraria em países como o Peru (20\%), Estados Unidos (3\%), demais países do Acordo da América do Norte (Nafta) (14\%), assim como a África (20\%) e os demais países da Ásia (16\%). Dada a sua representatividade na produção da carne de frango, os países do Nafta figurariam entre 
os maiores beneficiados, elevando sua produção em cerca de 1 milhão de toneladas, suprindo, assim, a redução da produção dos países do Mercosul e das demais regiões.

Essa significativa expansão produtiva do Peru se deve ao fato de que o país, em consequência do TPP, passa a exportar a carne de frango aos demais países do TPP, anteriormente atendidos pelos países do Mercosul. Igualmente, os Estados Unidos ampliam seu volume de produção, voltando seus excedentes exportáveis intrabloco, caso da majoração dos fluxos à Malásia, ao Japão, aos demais países do TPP e, principalmente à União Europeia; esse último, por sua vez, acaba reduzindo sua produção, muito em decorrência da competitividade dos preços norte-americanos, ao mesmo tempo em que passa a atender ao mercado da Arábia Saudita, antes abastecido pelo Brasil.

Outra região que amplia seu comércio com os outros membros do TPP são os demais países do Nafta, pois, sendo países membros do acordo, beneficiam-se das medidas de contenção tarifárias e não tarifárias. Apesar de a Austrália, o Japão e os demais países do TPP serem membros do TPP, essas regiões têm suas produções diminuídas, porém ampliam o comércio com outros membros do acordo, caso dos Estados Unidos, do restante do Nafta e do Peru, uma vez que a importação dessas regiões se torna mais vantajosa em termos comerciais.

Levando-se em consideração a produção das regiões examinadas, de maneira geral, observa-se que os países que apresentam ganhos de produção de carne de frango são os Estados Unidos, o México e o Canadá (pertencentes ao Nafta) e também o Peru. Além do mais, em alguns casos, a efetivação dos acordos comerciais tende a prejudicar a produção de países membros, como a União Europeia, a Austrália, a Malásia, o Japão e demais países do TPP. Conforme salienta Miyazaki (2013), nem sempre os acordos de preferências comerciais gerarão ganhos a todos os países membros do ponto de vista econômico, pois ocorre um processo de criação e desvio de comércio.

No caso dos países não membros, a redução é ainda mais expressiva, caso do Brasil e dos demais países do Mercosul. De maneira geral, em ambos os cenários simulados, o Brasil tem reduzida a produção, sendo ela mais acentuada na simulação do cenário 2, o qual pressupõe a formação do TPP, com a eliminação total das barreiras tarifárias e não tarifárias, seguida pela formação dos acordos simultaneamente e, de forma menos agressiva, dada a efetivação do TTIP, com a eliminação total das barreiras tarifárias e não tarifárias.
Esses resultados vão ao encontro dos achados de Silva et al. (2015), que verificaram a redução da produção de carnes e animais vivos do Mercosul decorrente da redução das tarifas do TTIP, porém, verificou-se o incremento da produção do Mercosul com a liberação total do comércio no acordo. Na mesma direção, Silva (2016) verificou que, em um cenário de redução tarifária no TTII, ocorrerá redução na produção de carnes e animais vivos na maioria das macrorregiões brasileiras; todavia, na liberação de comércio, o setor apresenta crescimento de sua produção.

\subsubsection{Análise dos excedentes do produtor e consumidor}

No primeiro cenário, que pressupõe a formação do TPP com eliminação parcial das barreiras tarifárias e manutenção das restrições de natureza não tarifárias, conforme propostas em discussão, observam-se pequenas mudanças nos países / regiões estudadas (ver Tabela 2). Para tanto, verifica-se que as alterações mais relevantes em termos de excedentes do produtor ocorreram na Austrália (0,7\%) e nos demais países da Asean (0,3\%), representando, em termos absolutos, ganhos de cerca de US\$ 20 e US\$ 21 milhões, respectivamente.

Por outro lado, no Brasil, observa-se redução nos excedentes do produtor, ainda que marginal, cerca de $0,1 \%$, o que perfaz perda de cerca de US\$ 22 milhóes aos produtores. $\mathrm{O}$ mesmo acontece com a Argentina $(0,1 \%)$ e com os demais países do Mercosul $(0,2 \%)$, cuja redução é de aproximadamente US\$ 3,5 milhões e US\$ 200 mil. Ainda, verifica-se redução nos demais países do Oriente Médio, na Arábia Saudita, no Japão e nos demais países do TPP decorrente da redução dos preços e do redirecionamento dos fluxos comerciais.

Tendo em vista o fortalecimento das relações comerciais entre os membros do TPP, a Austrália, que anteriormente exportava para o Asean, passa a exportar carne de frango para o Japão, mercado anteriormente atendido pelo Brasil. Essa configuração estimula os demais países do Asean a aumentarem sua produção e assim seus excedentes, mas, por sua vez, o processo contrário ocorre no Brasil.

No segundo cenário, que pressupõe livre comercialização entre os países membros do TPP (eliminação total das barreiras tarifárias e não tarifárias), as perdas do Brasil se tornam mais expressivas, sendo que tal retração 
Tabela 2. Variações dos excedentes do produtor nos cenários alternativos em relação ao cenário-base (\%)

\begin{tabular}{|c|c|c|c|c|c|}
\hline Região & Cenário 1 & Cenário 2 & Cenário 3 & Cenário 4 & Cenário 5 \\
\hline bra & $-0,1$ & $-13,9$ & 0,0 & $-5,2$ & $-11,5$ \\
\hline arg & $-0,1$ & $-12,2$ & 0,0 & $-4,2$ & $-9,4$ \\
\hline mcs & $-0,2$ & $-17,0$ & 0,0 & $-6,0$ & $-13,3$ \\
\hline per & 0,0 & 34,7 & 0,0 & 6,7 & 44,9 \\
\hline das & 0,0 & 0,5 & 0,0 & 0,0 & 2,4 \\
\hline usa & 0,0 & 5,5 & 0,0 & 4,9 & 6,8 \\
\hline naf & 0,0 & 23,9 & 0,0 & 21,1 & 30,2 \\
\hline aus & 0,7 & $-4,5$ & 0,0 & $-0,2$ & $-3,0$ \\
\hline mas & 0,0 & $-23,7$ & 0,0 & 0,0 & $-19,4$ \\
\hline ase & 0,3 & $-10,3$ & 0,0 & $-0,6$ & $-6,9$ \\
\hline afr & 0,0 & 40,7 & 0,0 & 36,1 & 45,3 \\
\hline ome & $-0,1$ & $-10,1$ & 0,0 & $-3,8$ & $-8,4$ \\
\hline sau & $-0,1$ & $-10,1$ & 0,0 & $-15,2$ & $-9,0$ \\
\hline jpn & $-0,1$ & $-13,7$ & 0,0 & $-1,9$ & $-12,4$ \\
\hline asi & 0,0 & 32,7 & 0,0 & 28,7 & 34,9 \\
\hline chn & 0,0 & 0,0 & 0,0 & 0,0 & 0,0 \\
\hline rus & 0,0 & 0,0 & 0,0 & 0,0 & 0,0 \\
\hline ue 28 & 0,0 & 0,0 & 0,0 & $-13,9$ & $-10,6$ \\
\hline tpp & $-0,1$ & $-13,6$ & 0,0 & $-3,8$ & $-9,5$ \\
\hline $\mathrm{rm}$ & 0,0 & $-1,0$ & 0,0 & 0,0 & 0,0 \\
\hline
\end{tabular}

Fonte: Resultados da pesquisa.

se aproxima dos $14 \%$, o que perfaz a redução de aproximadamente US\$ 2 bilhões aos produtores. Para o restante do Mercosul, a redução representa cerca de US\$22,5 milhões. Retração também ocorre em países como a Austrália (4,5\%), a Malásia $(23,7 \%)$, demais países do Asean (10,3\%), países do Oriente Médio (10\%), a Arábia Saudita (10\%), o Japão (13,7\%) e demais países do $\operatorname{TPP}(13,6 \%)$. Em destaque estão a Austrália, o Japão e os demais países do TPP, que, conjuntamente, representam redução de cerca de US\$ 15 milhões, US\$ 763 milhões e US\$ 356 milhões, respectivamente, aos produtores de carne de frango desses países.

Em contrapartida, alguns países apresentaram expressivo crescimento nos excedentes do produtor, caso do Peru (35\%), dos países do Nafta (24\%), dos países da África (41\%), dos países da Ásia (33\%), além dos Estados Unidos $(5,5 \%)$. No caso da África, esse incremento representa cerca de US\$1,3 bilhão aos produtores, enquanto que, para os países do Nafta como um todo, o incremento alcança US $\$ 6,6$ bilhões.

Assim sendo, constata-se que o comportamento dos excedentes do produtor se devem ao desvio de comércio decorrente da eliminação total das restrições comerciais entre os membros do TPP, beneficiando os países que apresentam maior produtividade, melhores condições de produção e preços mais competitivos intrabloco, caso do Peru, dos Estados Unidos e dos demais países do Nafta. Esses absorvem a fatia de comércio de membros como os demais países do TPP e do Japão, que anteriormente se destinava aos países do Mercosul. Tal processo também altera as condições de produção e comércio na África e na Ásia, que terão que buscar alternativas para atender à demanda interna, regiões essas que anteriormente tinham seu déficit de consumo de frango suprido pelo produto importado dos Estados Unidos.

Em relação ao Cenário 3, que supõe a redução em $40 \%$ das tarifas no TTIP, não foram observadas alterações em termos de excedentes de produtor e de consumidor, igualmente aos resultados obtidos à produção. Porém, quando simulado um cenário comercial mais agressivo no TTIP, caso do cenário 4, com a eliminação total das barreiras tarifárias e não tarifárias, essas alterações impactam de forma menos significativa o Brasil, se comparado com o TPP, sendo que a redução no excedente 
do produtor é de $5,2 \%$, equivalente a uma perda de cerca de US\$ 784 milhões. Retração semelhante também foi encontrada para o restante do Mercosul, onde a Argentina e os demais do Mercosul apresentaram reduções de $4,2 \%$ e $6,0 \%$, respectivamente.

Destaca-se a queda do excedente do produtor da União Europeia, de cerca de 14\% (equivale a US\$ 5,5 bilhões), embora constitua-se como membro do acordo. Apesar de a região passar a exportar à Arábia Saudita, verifica-se redução nos excedentes pela ocorrência do processo de reexportação, visto que o produto destinado à Arábia Saudita tem origem nos Estados Unidos. Isso ocorreria pela facilitação de comércio decorrente do acordo, tornando as negociações menos onerosas. Nesta conjuntura, a Arábia Saudita, principal parceiro comercial do Brasil no setor da carne de frango, também apresentaria redução nos excedentes do produtor, os quais se aproximariam de $15 \%$ devido à expansão da importação da commodity do bloco europeu.

Por outro lado, verifica-se um acréscimo significativo nos excedentes do produtor nos demais países do Nafta (21\%), nos países da África (36\%) e demais países da Ásia $(29 \%)$, pois a expansão do mercado norte-americano para a União Europeia, devido ao TTIP, em detrimento do volume exportado aos países do Nafta, África e Ásia, forçaria essas regiões a expandirem suas produções para atenderem suas demandas internas, impactando no bem-estar do produtor.

Por fim, quando estimada a ocorrência simultânea dos acordos TPP e TTIP (Cenário 5), os impactos foram menos expressivos quando comparados somente com a efetivação da parceria Transpacífico. No caso do Brasil, a perda de bem-estar dos produtores em função da redução da produção e das exportações seria de 11,5\% (ou US\$1,7 bilhão). Porém, de maneira geral, o mercado internacional tende a apresentar ganhos com a formação dos acordos, caso de países como o Peru (44\%), os países africanos (45\%), os países do Nafta (30\%) e os da Ásia (35\%). Estes ganhos também são observados nos Estados Unidos, que apresentaram acréscimo relativamente baixo em seu excedente do produtor, correspondente a US\$ 6,6 bilhões.

Este processo ocorre de forma semelhante ao verificado no cenário 4, porém os Estados Unidos voltam seu comércio para alguns membros do TPP e do TTIP, caso da Malásia, do Japão, dos demais países do TPP e também da União Europeia. Logo, a África, o
Nafta e os demais países da Ásia teriam que substituir suas relações comerciais de carne de frango, as quais eram atendidas pelos excedentes norte-americanos. Essa situação poderia levar os demais países da África a importar carne brasileira, devido à produção interna insuficiente. Ainda assim, os demais países do Nafta e o Peru beneficiaram-se, exportando aos países do TPP, decorrente da facilitação de comércio. Todavia, o Peru, dada sua capacidade produtiva limitada, importaria parte desse quantitativo do Brasil, caracterizando a reexportação, ao mesmo tempo em que as perdas dos produtores brasileiros tenderiam a ser minimizadas.

Complementando a análise do bem-estar, a Tabela 3 apresenta os excedentes do consumidor. No cenário 1, observam-se ganhos para os consumidores brasileiros, ainda que marginais, os quais são decorrentes da maior oferta doméstica de carne de frango. Ganhos que se elevam com o aprofundamento do Acordo do Transpacífico, caso do cenário 2 , em que a variação dos excedentes se aproxima dos $10 \%$. Já quando simulada a ocorrência do Acordo do Transatlântico, com a eliminação total das barreiras tarifárias e não tarifárias, os ganhos são menores comparativamente aos cenários 1 e 2, atingindo 3,4\% no cenário 4 . Tendo em vista que os fluxos comerciais são redirecionados, o Brasil apresentaria redução de preços, estimulando o consumo interno.

Quando examinada a situação da efetivação simultânea dos dois acordos (Cenário 5), o crescimento dos excedentes dos consumidores brasileiros se aproxima dos $8 \%$, com tais alterações representando um ganho de cerca de US\$1,6 bilhão. Essa configuração de comércio é semelhante ao ocorrido no cenário 4, porém, com a redução dos preços mais expressiva, espera-se um elevado crescimento da demanda interna.

Vale destacar que países como o Peru, os Estados Unidos, os demais países do Nafta, países da África e países da Ásia apresentaram significativas perdas em relação aos excedentes dos consumidores, em específico nos cenários 2, 4 e 5 . Novamente, no cenário 3, que simula apenas a redução de $40 \%$ das tarifas entre os Estados Unidos e União Europeia (membros do TTIP), as alterações comerciais em termos globais foram praticamente nulas. Este resultado se deve principalmente à manutenção das barreiras não tarifárias, não alterando, assim, as condições e os fluxos de comércio.

De outro lado, não foram observadas mudanças nas relações de comércio chinesas em nenhum dos cenários 
Tabela 3. Variações dos excedentes do consumidor nos cenários alternativos em relação ao cenário-base (\%)

\begin{tabular}{cccccc}
\hline Região & Cenário 1 & Cenário 2 & Cenário 3 & Cenário 4 & Cenário 5 \\
\hline bra & 0,1 & 9,6 & 0,0 & 3,4 & 7,8 \\
arg & 0,1 & 5,5 & 0,0 & 1,8 & 4,2 \\
mcs & 0,0 & 5,0 & 0,0 & 1,6 & 3,8 \\
per & 0,0 & $-23,2$ & 0,0 & $-5,3$ & $-28,7$ \\
das & 0,0 & $-0,4$ & 0,0 & 0,0 & $-2,0$ \\
usa & 0,0 & $-7,2$ & 0,0 & $-6,4$ & $-8,8$ \\
naf & 0,0 & $-14,8$ & 0,0 & $-13,2$ & $-18,1$ \\
aus & $-0,6$ & 3,6 & 0,0 & 0,2 & 2,4 \\
mas & 0,0 & 23,1 & 0,0 & 0,0 & 18,2 \\
ase & $-0,3$ & 12,3 & 0,0 & 0,6 & 8,1 \\
afr & 0,0 & $-30,3$ & 0,0 & $-27,6$ & $-32,9$ \\
ome & 0,1 & 7,0 & 0,0 & 2,5 & 5,7 \\
sau & 0,1 & 11,0 & 0,0 & 17,3 & 9,7 \\
jpn & 0,0 & 14,7 & 0,0 & 1,7 & 12,3 \\
asi & 0,0 & $-23,1$ & 0,0 & $-20,6$ & $-24,3$ \\
chn & 0,0 & 0,0 & 0,0 & 0,0 & 0,0 \\
rus & 0,0 & 0,0 & 0,0 & 0,0 & 0,0 \\
ue28 & 0,0 & 0,0 & 0,0 & 20,1 & 14,7 \\
tpp & 0,1 & 12,0 & 0,0 & 3,1 & 8,1 \\
rm & 0,0 & 0,6 & 0,0 & 0,0 & 0,0 \\
\hline
\end{tabular}

Fonte: Resultados da pesquisa.

simulados. Possivelmente, pelo fato de que o país asiático consegue atender boa parte da demanda interna com a produção local, possuindo baixa dependência do mercado externo. Todavia, Aslan et al. (2015) estimaram perdas significativas para a economia chinesa na ocorrência do TPP, TTIP, ou na ocorrência simultânea desses acordos, a partir da análise das variáveis econômicas, como o PIB, importações e exportações.

Em síntese, a partir das simulações dos cenários alternativos, verificou-se que o Brasil, assim como os países do Mercosul em geral, apresentariam perdas em termos de excedentes do produtor na formação do TPP, assim como do TTIP. Resultado que corrobora o encontrado por Silva et al. (2015), que verificaram redução de bem-estar do Mercosul em dois cenários, um de redução tarifária e outro de liberação de comércio no TTIP.

A partir desse mesmo cenário, de eliminação tarifária no TTIP, Lima et al. (2014) verificaram ganhos de bem-estar para os Estados Unidos e União Europeia, porém, o agronegócio brasileiro incorreria em perdas de bem-estar próximas a US\$ 600 milhões, além da redução na exportação do setor como um todo. Na mesma linha,
François et al. (2013) afirmam que, dada a formação do TTIP em um cenário ambicioso ou menos ambicioso, a União Europeia e os Estados Unidos apresentariam ganhos significativos.

Além disso, presumem-se impactos positivos para o resto do mundo, diferentemente do que foi verificado no estudo, ganhos aos Estados Unidos e perdas à União Europeia e para o Brasil. Entretanto, alinha-se com os achados de Petri \& Plummer (2016), que obtiveram resultados de que o TPP irá beneficiar substancialmente os seus membros, em particular aumentará os rendimentos dos Estados Unidos, principalmente suas exportações.

Em síntese, fazendo análise pormenorizada dos impactos nos excedentes do produtor e do consumidor no Brasil, constata-se que o País apresenta ganhos inferiores à perda dos produtores, ocasionando em perda líquida em termos de bem-estar a partir deste novo enquadramento global de comércio. Na sequência e de forma complementar, são discutidas as alterações nos fluxos comerciais tendo em vista a simulação dos cenários alternativos. 


\subsubsection{Análise dos fluxos comerciais}

As mudanças nos fluxos comerciais nas regiões estudadas decorrentes da simulação dos acordos propostos finalizam a análise em que são enfatizadas principalmente as alterações nos fluxos comerciais do Brasil, no que tange aos mercados importadores e o direcionamento do produto brasileiro, alterações que estão ilustradas na Figura 1. No cenário-base, o Brasil exporta seus excedentes de carne de frango aos países do Oriente Médio, em destaque a Arábia Saudita e também ao Japão e a alguns outros membros do TPP, caso do Chile, da Nova Zelândia, de Brunei, de Cingapura e do Vietnã. Ressalta-se a carne de frango brasileira destinada

Figura 1. Fluxos comerciais do Brasil nos cenários alternativos

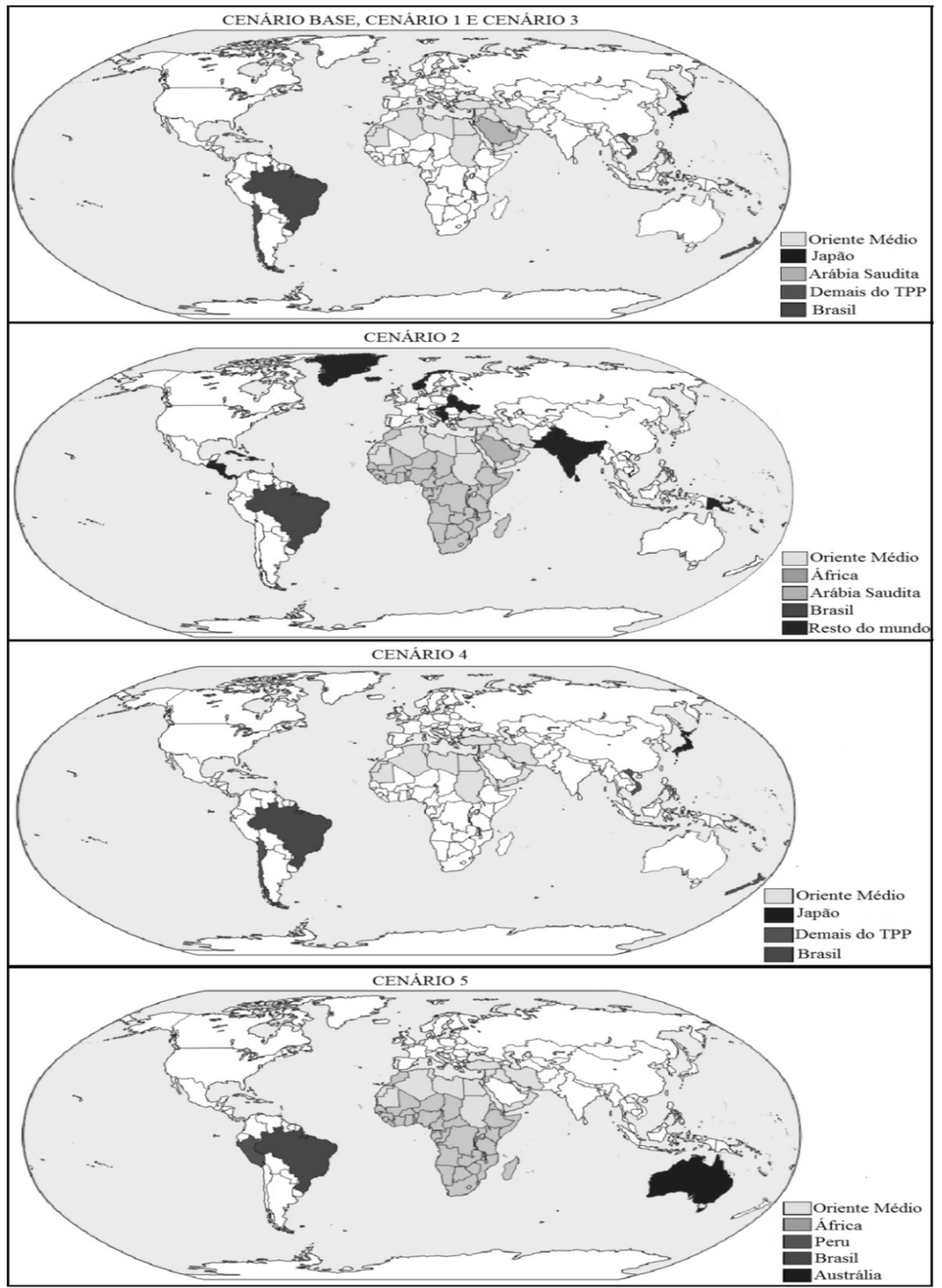

Fonte: Elaborado pelos autores. Nota: As ilustrações demonstram unicamente os fluxos comerciais do Brasil decorrente das simulações realizadas. 
a outros inúmeros países, sendo que, em 2015, esse quantitativo atingiu 145 países (Brasil, 2016).

Com a simulação do Cenário 1, as tarifas dos membros do TPP foram reduzidas, impactando negativamente nas exportações brasileiras, o que se refletiu na maior oferta interna, pressionando os preços e, como consequência, aumentando o consumo interno. Além do mais, o País expande sua exportação ao Oriente Médio, à Arábia Saudita e aos demais países do TPP, em detrimento das importações ao Japão, o qual passa a importar parte de sua demanda da Austrália, outro membro do TPP, decorrente da facilitação de comércio provocada pelos termos do acordo.

No cenário de maior liberalização comercial do TPP (cenário 2), o fluxo comercial entre o Brasil e o Oriente Médio reduz aproximadamente $90 \%$, sendo que esse último passa a importar do Japão, que, por consequência, direciona integralmente suas importações aos Estados Unidos. Já as exportações do Brasil para os demais membros do TPP são totalmente interrompidas, passando estes a importar o produto do Peru, dos Estados Unidos e dos demais países do Nafta, membros do referido acordo.

Em contrapartida, o Brasil amplia suas exportações à Arábia Saudita e também passa a exportar aos países da África, os quais tinham sua demanda suprida pelas exportações dos Estados Unidos. Em linha com esta discussão, Burfisher et al. (2014) verificou que o Japão absorveria o comércio agrícola principalmente dos países do TPP, aproximadamente 70\% do aumento do comércio agrícola e que os Estados Unidos também captariam parte das exportações agrícolas dentro do Acordo Transpacífico (cerca de um terço). Além disso, haveria aumento do comércio intrabloco de carnes bovina e de aves, beneficiando essencialmente a Austrália, os Estados Unidos, o Canadá e a Nova Zelândia. Estes resultados também vão ao encontro dos achados de Thorstensen \& Ferraz (2014b), que afirmam que o TPP deve apresentar impactos negativos à economia brasileira, podendo ser mais significativos com os ganhos de competitividade dos países-membros do acordo.

No cenário 3, que considera unicamente a eliminação parcial das barreiras tarifárias entre Estados Unidos e União Europeia, não foram observadas importantes alterações nos fluxos comerciais (na Figura 1, os fluxos são similares ao do cenário 1). Todavia, quando simulado o cenário 4, a eliminação total das barreiras tarifárias e não tarifárias provocou alterações significativas nos fluxos comerciais, que se concentraram na ampliação dos fluxos entre o Brasil e o Oriente Médio (26\%), Brasil e Japão (6\%), além dos demais membros do TPP (41\%). Por outro lado, verifica-se perda do mercado da Arábia Saudita à União Europeia, similarmente ao constatado por Berden et al. (2009), quando estimaram os impactos do TTIP nos países-membros, encontrando evidências de crescimento do PIB e das exportações dos Estados Unidos e da União Europeia nos diversos setores.

Neste mesmo contexto, Thorstensen \& Ferraz (2014b) verificaram que, com a eliminação total das barreiras não tarifárias entre os Estados Unidos e a União Europeia, os impactos negativos ao Brasil são mais significantes e, caso o Brasil participasse do acordo, apresentaria crescimento na maioria dos setores agrícolas.

Por fim, com a simulação da ocorrência simultânea dos acordos, o Brasil é impactado pela redução da demanda de carne de frango dos seus principais parceiros comerciais, caso da Arábia Saudita e do Japão, que direcionam suas importações à União Europeia e para os Estados Unidos, respectivamente. Por outro lado, as exportações brasileiras são direcionadas ao Oriente Médio (crescimento de aproximadamente $60 \%$ ), além de passar a comercializar com o Peru e a Austrália, fluxo não verificado nos demais cenários. Percebe-se que, a partir desse cenário, os Estados Unidos centralizam suas relações comerciais com os membros dos acordos, como a Malásia, o Japão, a União Europeia e os demais países do TPP, assim como a União Europeia reduz sua demanda interna e passa a exportar à Arábia Saudita.

\section{Conclusões}

Considerando-se a formação de novos acordos comerciais, o estudo analisou os possíveis impactos da formação do Acordo Transpacífico e do Acordo Transatlântico sobre o mercado de carne de frango brasileiro, utilizando para tal a modelagem de Equilíbrio Espacial e do Problema de Complementaridade Mista (PCM). As possíveis alterações de comércio foram obtidas por meio da simulação de cinco cenários alternativos, que seguiram as propostas de redução estabelecidas nas referentes negociações.

O cenário 1 configura a formação do TPP com a redução de $40 \%$ das barreiras tarifárias, enquanto que o 
cenário 2 supôs a eliminação total das barreiras tarifárias e também não tarifárias aos países membros. Para o TTIP, foram simulados os cenários 3 e 4, os quais igualmente consideraram a redução de $40 \%$ das tarifas e eliminavam as barreiras tarifárias e não tarifárias. Já no cenário 5 foi simulada a efetivação simultânea de ambos os acordos, sendo considerada a eliminação integral das barreiras tarifárias e não tarifárias.

A partir dos resultados, de maneira geral, constatou-se que a efetivação de ambos os acordos pode invariavelmente trazer prejuízos ao setor brasileiro de carne de frango, principalmente no que se refere à produção, que apresenta retração em ambos os cenários e, em consequência, afeta os preços e os excedentes dos produtores. Percebe-se que os cenários mais prejudiciais ao Brasil consistem na formação do TPP em sua forma mais ampla, baseando-se na eliminação das barreiras tarifárias e não tarifárias, como também na formação simultânea dos acordos. Em ambos os cenários, apesar de o País apresentar ganhos em relação aos excedentes do consumidor, em razão da maior oferta interna, esses não são suficientes para equilibrar as perdas dos produtores, gerando ao país uma perda líquida de bem-estar.

Sobre isso, salienta-se a importância de negociações de acordos comerciais pelo Brasil considerando políticas e medidas voltadas à ampliação/acesso de mercados e à manutenção das condições competitivas para que o País acompanhe as mudanças do cenário global; também faz-se importante alinhar-se às cadeias globais para minimizar os efeitos da redução de mercados importantes devido a políticas comerciais contracionistas. Ademais, deve-se considerar que essas alterações podem impactar em outros setores, ainda que de forma indireta, caso das demais carnes, tendo em vista que a carne de frango é um produto substituto para os produtos cárneos.

Paralelamente, em âmbito interno, medidas também são necessárias. Apesar de ter apresentado, nos últimos anos, avanços relacionados à genética, à sanidade e à nutrição, que garantiram a melhoria na qualidade do produto e um aumento no valor agregado, o setor deve, ainda, direcionar-se à alocação eficiente de recursos para ampliar a capacidade produtiva, apresentando rigor nas questões relacionadas à saúde animal, assim como na fiscalização e na certificação dos produtos em todos os elos da cadeia, pois esses aspectos de natureza técnica têm grande potencial de distorção dos fluxos de comércio internacionalmente. Essas ações podem ser viabilizadas por meio da interação da cadeia, dado que o setor apresenta, em sua maioria, um sistema produtivo baseado na integração verticalizada, o que tem contribuído para seu desenvolvimento, redução de custos e maximização dos resultados.

Embora os resultados tenham demonstrado consistência, retratando as condições comerciais reais, pode-se destacar que existem limitações, principalmente pelo fato das elasticidades se referirem às carnes de maneira geral, as quais foram publicadas em 2003. Para isso, foram realizados ajustes de forma a atender aos critérios de calibragem. Também se destaca a inexistência de informações específicas relacionadas ao custo de transporte marítimo da carne de frango, com o que se fez o uso de estimativas, conforme as informações referentes tarifas portuárias disponíveis pelo porto de Rio Grande.

Por fim, para estudos futuros relacionados à análise de condições comerciais no setor de carne de frango, sugere-se a análise de cenários que incluam alterações nos subsídios, visto que tais mudanças possuem influência nos fluxos comerciais internacionais, embora não tenham sido foco nos acordos TPP e TTIP. Também sugere-se a simulação da participação de países não membros nos acordos em questão, como o Brasil e a China, bem como a reestruturação de acordos já existentes, caso da União Europeia.

\section{Referências}

Alvim, A. M. (2010). As consequências dos acordos de livre comércio sobre o setor de lácteos no Brasil. Revista de Economia e Sociologia Rural, 48(2), 405-428.

Alvim, A. M., \& Waquil, P. D. (2007). Os efeitos do livre comércio sobre o mercado de grãos no Brasil. Análise Econômica, 25(47), 23-42.

Aslan, B., Kutuk, M. M., \& Oduncu, A. (2015). Transatlantic trade and investment partnership and trans-pacific partnership: policy options of China. China $\mathcal{E}$ World Economy, 23(6), 22-43. Recuperado em 06 de janeiro de 2016, de http: / / onlinelibrary.wiley.com/doi/10.1111/ cwe.12134/full.

Avisite (2015). Principais países produtores de frango da União Europeia. Campinas. Recuperado em 21 de novembro de 2016, de http:/ / www.avisite.com.br/noticias/index. php?codnoticia $=15756$

Bender Filho, R., \& Alvim, A. M. (2007). O mercado de carne bovina no Brasil: os efeitos da eliminação das 
barreiras tarifárias e não-tarifárias. Revista de Economia e Sociologia Rural, 46(4), 1095-1127.

Berden, K., Francois, J., Thelle, M., Wymenga, P., \& Tamminen, S. (2009). Non-tariff measures in EU-US trade and investment-an economic analysis (237 p.). Rotterdam. Recuperado em 6 de janeiro de 2016, de http:// trade.ec.europa.eu/doclib/docs / 2009/ december/ tradoc_145613.pdf

Brasil. Ministério do Desenvolvimento Indústria e Comércio Exterior - MDIC. (2016). Simulador de preço de exportação. Brasília. Recuperado em 01 de maio de 2016, de http:/ / simuladordepreco.mdic.gov.br/

Burfisher, M. E., Dyck, J., Meade, B., Mitchell, L., Wainio, J., Zahniser, S., Arita, S., \& Beckman, J. (2014). Agriculture in the Trans-Pacific Partnership. Washington: USDA-ERS Economic Research. Recuperado em 27 de janeiro de 2016, de http:/ / www.ers.usda.gov/media/1692500/ err176_summary.pdf

Centre for Economic Policy Research - CEPR. (2013). Impact Assessment Report on the future of EU-US trade relations. Strasbourg. Recuperado em 13 de janeiro de 2016, de http:/ / trade.ec.europa.eu/ doclib/ docs/2013/ march/tradoc_150759.pdf

European Comission. (2016). Report of the 14th Round of Negotiations. Bruxelas. Recuperado em 1 de outubro de 2016, de http:/ / trade.ec.europa.eu/doclib/docs/2016/ august/tradoc_154837.pdf

Food and Agricultural Organization of the United Nations - FAO. (2016). FAO Statistics Series. Roma. Recuperado em 02 de fevereiro de 2016, de http:/ / faostat3.fao.org/home/

François, J., Manchin, M., Norberg, H., Pindyuk, O., \& Tomberger, P. (2013). Reducing transatlantic barriers to trade and investment - an economic assesment, Centre for Economic Policy Research. Recuperado em 6 janeiro de 2016, de https://ideas.repec.org/p/lnz/ wpaper/20130401.html

Gründling, R. D. P., \& Waquil, P. D. (2015). Efeitos de acordos comerciais sobre o setor de carne bovina no MERCOSUL. Revista de Economia e Agronegócio - REA, 5(4), 567-590.

Lima, C. Z., Goncalves, M. F., \& Teixeira, E. C. (2014). Impacts of a trade liberalization agreement between the United States and the European Union on Brazilian Agribusiness. In Proceedings of the $5^{o}$ Regional Meeting: Public Policy Analysis with Computable General Equilibrium Models. Bogota, Colombia: PPAC. Recuperado em 06 de janeiro de 2016, de http:/ / www.paeg.ufv.br/wp-content/ uploads/Cicero-Zanetti-de-Lima.pdf

Miyazaki, S. Y. M. (Org.). (2013). Integração econômica regional (1. ed.). São Paulo: Saraiva.

Monteiro, S. (2014). Prova de força. Revista Conjuntura Econômica, 68(4), 34-37. Recuperado em 06 jan. 2016 de http:/ / bibliotecadigital.fgv.br/ojs/index.php/rce / article/view/31706/30498

Organização Mundial do Comércio - OMC. (2016). Portal Integrado de Informação Comercial. Genebra. Recuperado em 01 de maio de 2016, de http:/ /i-tip.wto.org/goods / Default.aspx

Organization for Economic Co-operation and Development - OECD. (2005). Agricultural Policies in OECD countries Monitoring and Evaluation 2005. Paris. Recuperado em 01 de maio de 2016, de http:/ / www.oecd.org/tad/ agricultural-policies/35016763.pdf

Petri, P. A., \& Plummer, M. G. (2016). The economic effects of the trans-pacific partnership: new estimates (Working Paper, 16-2). Washington: Peterson Institute for International Economics. Recuperado em 26 de outubro de 2016, de https:/ / piie.com/system/files/documents/wp16-2_0.pdf.

Porto do Rio Grande. (2016). Tarifa portuária. Rio Grande. Recuperado em 01 de maio de 2016, de http:/ / www. portoriogrande.com.br/site/estrutura_portuaria_tarifas. php

Samuelson, P. A. (1952). Spatial price equilibrium and linear programming. The American economic review, 42(3), 283-303. Recuperado em 06 de janeiro de 2016, de ttp: / / www.jstor.org/stable/pdf/1810381.pdf?acceptTC=true

Silva, M. L. (2016). O impacto da Parceria Transatlântica de Comércio e Investimento (TTIP) nas macrorregiões brasileiras (Dissertação de mestrado). Programa de Pós-graduação em Administração, Universidade Federal de Santa Maria. Santa Maria.

Silva, M. L., Coronel, D. A., \& Silva, R. A. (2015). O impacto da Parceria Transatlântica de Comércio e Investimento (TTIP) para os principais parceiros comerciais do Brasil: China e MERCOSUL. In Anais do $13^{\circ}$ Encontro Nacional da Associação Brasileira de Estudos Regionais Urbanos. Curitiba: ENABER. Recuperado em 06 de janeiro de 2016, de http: / / www.brsa.org.br/fotos/artigo1-2015-05-31-00-59-11.pdf

Sousa, D. P., \& Osaki, M. (2005). Caracterização do mercado internacional de carne de frango Brasil $x$ Estados Unidos. In Anais do $43^{\circ}$ Congresso da Sociedade Brasileira de Economia e Sociologia Rural. Ribeirão Preto: SOBER. Recuperado em 20 de janeiro de 2016, de http: / / www. cepea.esalq.usp.br/pdf/Sober_Danusa.pdf.

Thorstensen, V. (2012). Impactos da crise econômica e financeira na regulação do comércio internacional. (Boletim de Economia e Política Internacional, 12). Recuperado em 08 de fevereiro de 2016, de http:/ / repositorio.ipea. gov.br/bitstream/11058/4456/1/BEPI_n12_impacto.pdf

Thorstensen, V., \& Ferraz, L. (2014a). O isolamento do Brasil em relação aos acordos e mega-acordos comerciais. (Boletim de Economia e Política Internacional). Recuperado em 09 de março de 2016, de http:// repositorio.ipea.gov. br/bitstream/11058/3762/1/BEPI_n16_isolamento.pdf 
Thorstensen, V., \& Ferraz, L. (2014b). The impacts of TTIP and TPP on Brazil. São Paulo: Fundação Getúlio Vargas. Recuperado em 18 de janeiro de 2016, de http:/ / ccgi. fgv.br/sites/ccgi.fgv.br/files/file/ Publicacoes/TTIP\%20 e\%20TPP\%20(ENG)\%2016.01,14.pdf

United States Department of Agriculture Foreign Agricultural Service - USDA. (2016a). World supply and distribution online. Washington. Recuperado em 20 de janeiro de 2016, de http: / / www.fas.usda.gov/ psdonline

United States Department of Agriculture Foreign Agricultural Service - USDA. (2016b). Commodity and Food Elasticities. Washington: USDA. Recuperado em 20 de maio de 2016, de http://www.ers.usda.gov/ data-products / commodity-and-food-elasticities.aspx
United States Trade Representative - USTR. (2014). 18,000 Tax Cuts on Made-in-America exports: a guide to how tax cuts will benefit exporting in your state. Washington: USTR. Recuperado em 20 de janeiro de 2016, de https: / / ustr. gov/sites/default/files/TPP-Guide-to-18000-Tax-Cuts.pdf

United States Trade Representative - USTR. (2015). Tariff Elimination Schedule. Washington: USTR. Recuperado em 02 de fevereiro de 2016, de https://ustr.gov/ trade-agreements / free-trade-agreements/trans-pacificpartnership/tpp-full-text

Waquil, P. D. (1995). Primal-dual spatial equilibrium model with intermediate products: application to the agricultural sector in the MERCOSUR. (Doctoral dissertation). University of Wisconsin, Madison. 